\title{
Erratum to: Stance Sub-phases Gait Event Detection in Real-Time for Ramp Ascent and Descent
}

Hafiz F. Maqbool, Muhammad A.B. Husman, Mohammed I. Awad, Alireza Abouhossein, Nadeem Iqbal and Abbas A. Dehghani-Sanij

\section{Erratum to: \\ Chapter "Stance Sub-phases Gait Event Detection in Real-Time for Ramp Ascent and Descent" in: J. Ibáñez et al. (eds.), Converging Clinical and Engineering Research on Neurorehabilitation II, Biosystems \& Biorobotics 15, DOI 10.1007/978-3-319-46669-9_34}

The book was inadvertently published with incorrect author affiliations in Chapter "Stance Sub-phases Gait Event Detection in Real-Time for Ramp Ascent and Descent". The erratum chapter has been updated with correct author affiliations.

The updated original online version for this chapter can be found at DOI 10.1007/978-3-319-46669-9_34

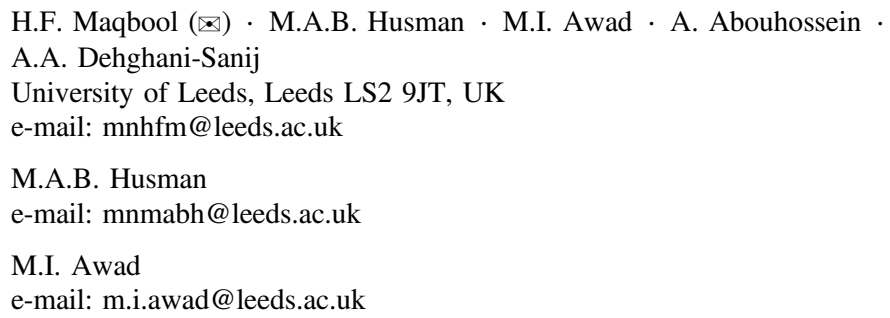

A. Abouhossein

e-mail: a.abouhossein@leeds.ac.uk

A.A. Dehghani-Sanij

e-mail: a.a.dehghani-sanij@leeds.ac.uk

H.F. Maqbool

University of Engineering and Technology of Lahore, Lahore, Pakistan

M.I. Awad

Ain Shams University, Cairo, Egypt

N. Iqbal

Abdul Wali Khan University Mardan, Mardan, Pakistan

e-mail: nikhan@awkum.edu.pk 